\title{
Application of Leslie's model on a population of common dolphins (Delphinus delphis): Sensitivity study
}

\author{
Spyros Fifas ${ }^{\left(1_{*}\right)}$, Michel Goujon ${ }^{(2)}$, Loïc Antoine ${ }^{(1)}$ \\ (1) Ifremer, Centre de Brest, DRV/RH, B.P. 70, 29280 Plouzané, France. \\ (2) ENSA, Département halieutique, 65, rue de Saint-Brieuc, 35042 Rennes, France. \\ Received July 8, 1997: revised June 1998; accepted Octoher 28, 1998
}

\begin{abstract}
The rapid development of the albacore tuna (Thunnus alalunga) driftnet fishery in the Bay of Biscay (Atlantic ocean, France) has incited European management authorities to ask for a study of its ecological impact on populations of common dolphins and striped dolphins. A programme with onboard observers has been led during 1992 and 1993, and a sighting survcy has allowed the evaluation of the abundances of fractions of populations in the studied area. For the population of common dolphins, the biological parameter estimation has allowed the building of a discrete age-structured model based on a Leslie matrix. Sensitivity studies have been conducted using four model parameters (age of first reproduction, interval between births, juvenile and adult survival rates). Results show that the increase rate of the population presents the highest sensitivity versus adult survival rate and, in second place versus the interval between births. (C) Ifremer/Elsevier, Paris
\end{abstract}

Linear model / common dolphin / driftnet fishery / survival rate

Résumé - Application du modèle de Leslie sur une population de dauphins communs (Delphinus delphis) : Étude des sensibilités. Le développement rapide de la pêche au thon germon (Thunnus alalunga) au filet maillant dérivant dans le golfe de Gascogne a incité les instances de gestion européenne à demander une étude de son impact écologique sur les populations de dauphin commun et de dauphin bleu et blanc. Des observateurs embarqués à bord ont mené au cours des années 1992 et 1993 une campagne d'échantillonnage sur un parcours linéaire, ce qui a permis d'estimer l'abondance des fractions de populations présentes sur la zone étudiée. Pour la population de dauphins communs, l'estimation des paramètres biologiques a permis de construire un modèle à pas discret structuré en âge faisant appel à une matrice de Leslie. Des études de sensibilité ont été réalisées selon quatre paramètres du modèle : âge de première mise bas, intervalle entre mises bas, taux de survie des juvéniles, taux de survie des adultes sur les deux sexes confondus. Les résultats montrent que le taux d'accroissement de la population préscnte la plus forte sensibilité, en fonction du taux de survie des adultes avec, en deuxième ordre, l'intervalle entre mises bas. $\mathcal{C}$ Ifremer/Elsevier, Paris

Modèle linéaire / dauphin commun / pêche au filet maillant dérivant / taux de survie

\section{INTRODUCTION}

The development, since the second half of the 1980 s, of the driftnet fishery targeting albacore tuna (Thunnus alalunga) in the Bay of Biscay has caused European management authorities to undertake a scientific study to analyze the ecological effects of this fishing activity. The study focused on the populations of common dolphins, Delphinus delphis, and striped dolphins, Stenella coeruleoalba.

Besides common dolphins, others species, mostly marketable cases of high market-value, are mentioned as bycatches or accidental catches by the French albacore tuna driftnet fishery $[1,2]$. The most widespread species are the swordfish (Xiphias gladius), the blue shark (Prionace glauca), the angelfish (Brama brama) and the wreckfish (Polyprion americanus). The media sensitivity focus on the common dolphin is due to its perception by man and demonstrates the deep historical bonds that exist between the two. Generally, whatever the fishing gcar used, fishing activities targeting tuna induce additional mortalities of marine mammals [1]. The European administration's particular interest in driftnet fishing is due to its spectacular develop- 
ment and to the social and political context but will not be analyzed by this study.

A research programme was conducted in 1992 and 1993, which allowed the estimation of the number, the frequency and the distribution of marine mammal accidentally caught [15]. A direct assessment of dolphin numbers in the fishing area was also initiated in 1993.

Biological parameter estimations of the population of common dolphins have allowed us to build a model of age-structured population dynamics to determine the increase in population rate according to specific input parameters. We used discrete models suited to large mammal populations with delayed maturation, a long life span and where individual age can be estimated [3]. These types of models have been used on terrestrial populations [13] and in marine species such as the Pribilof island fur seal [7], the British grey seal $[17]$, the common dolphin $[14,16,25]$ or the porpoise [26] and they can be used as a basis for management $[8,25]$

This study develops a simple age-structured model for common dolphin population dynamics and performs a sensitivity analysis of the increase rate of this population against four parameters: age of first reproduction, interval between births, and juvenile and adult survival rates.

\section{MATERIALS AND METHODS}

\subsection{Transition matrices}

Transition matrices models belong to the so-called discrete time models because they describe variations during non-infinitely small time intervals, named $\Delta t$. In general, these intervals are constant and are considered as time units $(\Delta t=1)$. A discrete time model is shown as follows $\mathrm{N}_{t+1}=\Psi\left(\mathrm{N}_{t}\right)(\Psi=$ function). In a transition matrices model $\mathrm{N}_{t+1}=\mathbf{U} \cdot \mathrm{N}_{t}$, where $\mathrm{U}$ is a population matrix and $\mathrm{N}_{t}, \mathrm{~N}_{t+1}$ are vectors. Accordingly, if we know the demographic structure at time $t$, then we will be able to know it at time $t+1$.

To calculate this demographic structure, it is necessary to concentrate only on the female fraction of the population, or on the product number of animals and of the sex ratio values fixed a priori by age group. The transition matrix allows us to pass from the vector giving the composition of the population at time $t$ (state vector) to the vector giving the composition of the population at time $t+1$.

In its simplest form, this matrix is made up of two types of parameters.

- (i) An expression of fecundity by age group $\left(b_{i}\right)$. Its value corresponds to the average number of females born at the end of a time unit, and the number of mothers in age group $i$ at the end of the previous interval.
- (ii) A survival probability during the time interval $s_{1}, \ldots, s_{i}, \ldots, s_{n}$ perhaps depending on corresponding age $1, \ldots, i, \ldots, n$.

The transition matrix (Leslie matrix; [20]) is presented as follows:

$$
\Lambda=\left[\begin{array}{cccc}
b_{1} & \ldots & b_{n-1} & b_{n} \\
s_{1} & \ldots & 0 & 0 \\
\cdot & \ldots & \cdot & . \\
0 & \ldots & s_{n-1} & 0
\end{array}\right]
$$

The discrete time model is based on the multiplication of this matrix by the state vector at time $t$. Regarding long-term trends, we proceed by recurrence stepping back as far as the state vector of the population at time 0:

$$
\mathrm{N}(t)=\Lambda^{t} \cdot \mathrm{N}(0)
$$

It is possible to demonstrate that the long-term evolution of the population is dependent on the greatest eigen value of the $\Lambda$ matrix. If this value, represented by $\lambda$, is positive, the population develops exponentially; if it is negative, the population is subject to fluctuations. If $\lambda>1$, the population increases; if $0<\lambda<1$, the population decreases and tends to 0 .

If we wish to know the long-term trends of the population, we must solve in $\lambda$ the following equation, called the Lotka equation [22], obtained by diagonal transformation of the matrix $\Lambda$ (equation (1)):

$$
\sum_{i=1}^{n} \frac{b_{i}}{s_{i}} \prod_{j=1}^{i} \frac{s_{j}}{\lambda}=1
$$

i.e.

$$
\sum_{i=1}^{n} \frac{b_{i}}{\lambda^{i}} \prod_{j=1}^{i-1} s_{j}=1
$$

\subsection{Lotka equation of common dolphin}

The Leslie matrix and the Lotka equation have already been used on dolphin populations [25]. In the case of common dolphins in the Bay of Biscay, a linear model of population dymamics has already been presented [16]. The following biological parameters are necessary in the model: (i) reproductive parameters: sex ratio (SR), age of first reproduction (AFR), interval between births (IB); and (ii) survival parameters: life span $\left(t_{\text {max }}\right)$, aduit survival rate $(A S)$, juvenile survival rate (JS).

\subsection{Input biological parameters}

\subsubsection{Reproductive parameters}

- Sex ratio (SR). The parameter necessary for the Lotka equation is the sex ratio at birth. If we assume that vulnerability of population does not depend on 
Table I. Asymptotic trend of the dolphin population (expressed by the first eigen value, $\lambda$, of the Lotka equation) against four model parameters: AFR (age of first reproduction), IB (interval between births), AS (adult survival rate) and JS (juvenile survival rate).

\begin{tabular}{|c|c|c|c|c|}
\hline $\begin{array}{c}\text { AFR } \\
\text { (years) }\end{array}$ & $\begin{array}{c}\text { IB } \\
\text { (years) }\end{array}$ & AS & JS & $\lambda$ \\
\hline 7 & 2 & 0.85 & 0.60 & 0.928 \\
\hline 7 & 2 & 0.85 & 0.70 & 0.938 \\
\hline 7 & 2 & 0.90 & 0.60 & 0.979 \\
\hline 7 & 2 & 0.90 & 0.80 & 0.998 \\
\hline 7 & 2 & 0.95 & 0.60 & 1.029 \\
\hline 7 & 2 & 0.95 & 0.90 & 1.059 \\
\hline 7 & 3 & 0.85 & 0.60 & 0.903 \\
\hline 7 & 3 & 0.85 & 0.70 & 0.912 \\
\hline 7 & 3 & 0.90 & 0.60 & 0.953 \\
\hline 7 & 3 & 0.90 & 0.80 & 0.971 \\
\hline 7 & 3 & 0.95 & 0.60 & 1.002 \\
\hline 7 & 3 & 0.95 & 0.90 & 1.029 \\
\hline 9 & 2 & 0.85 & 0.60 & 0.916 \\
\hline 9 & 2 & 0.85 & 0.70 & 0.925 \\
\hline 9 & 2 & 0.90 & 0.60 & 0.967 \\
\hline 9 & 2 & 0.90 & 0.80 & 0.984 \\
\hline 9 & 2 & 0.95 & 0.60 & 1.018 \\
\hline 9 & 2 & 0.95 & 0.90 & 1.043 \\
\hline 9 & 3 & 0.85 & 0.60 & 0.895 \\
\hline 9 & 3 & 0.85 & 0.70 & 0.903 \\
\hline 9 & 3 & 0.90 & 0.60 & 0.944 \\
\hline 9 & 3 & 0.90 & 0.80 & 0.960 \\
\hline 9 & 3 & 0.95 & 0.60 & 0.994 \\
\hline 9 & 3 & 0.95 & 0.90 & 1.018 \\
\hline 11 & 2 & 0.85 & 0.60 & 0.907 \\
\hline 11 & 2 & 0.85 & 0.70 & 0.915 \\
\hline 11 & 2 & 0.90 & 0.60 & 0.957 \\
\hline 11 & 2 & 0.90 & 0.80 & 0.973 \\
\hline 11 & 2 & 0.95 & 0.60 & 1.008 \\
\hline 11 & 2 & 0.95 & 0.90 & 1.030 \\
\hline 11 & 3 & 0.85 & 0.60 & 0.888 \\
\hline 11 & 3 & 0.85 & 0.70 & 0.895 \\
\hline 11 & 3 & 0.90 & 0.60 & 0.937 \\
\hline 11 & 3 & 0.90 & 0.80 & 0.951 \\
\hline 11 & 3 & 0.95 & 0.60 & 0.986 \\
\hline 11 & 3 & 0.95 & 0.90 & 1.008 \\
\hline
\end{tabular}

sex, this parameter is expressed as the proportion of females to the total number of adult individuals for the whole life cycle. In the case of marine mammals, sex ratio estimation by direct assessment is often biased because of space-time variability of sexual segregation [24] unless done on a large sample of fetuses. Despite instability of this parameter, results obtained by direct assessment [14] do not invalidate the hypothesis of an equivalent presence of two sexes in the target population. The value for SR is fixed at 0.5 [14].

- Age of first reproduction (AFR). Beyond this age, a positive fecundity value, for simplification, is considered as a constant. This parameter varies between 7 and 11 years according to the literature [14].

- Interval between births (IB). It is involved in fecundity calculation for ages above or equal to AFR. The average number of females born, during a time interval of a year which represents fecundity, is a product of the sex ratio and the adult survival rate divided raised by Reilly and Barlow [25]. This parameter var-
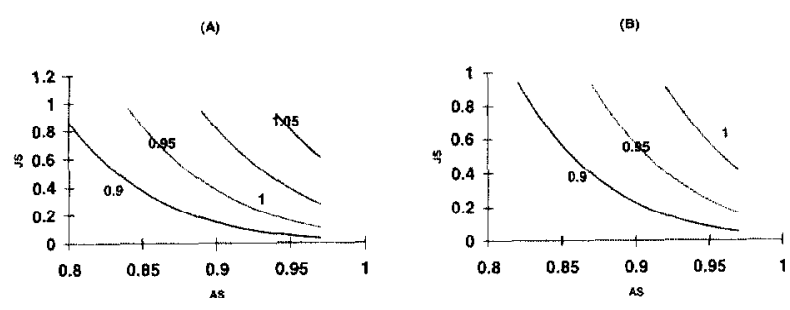

(C)

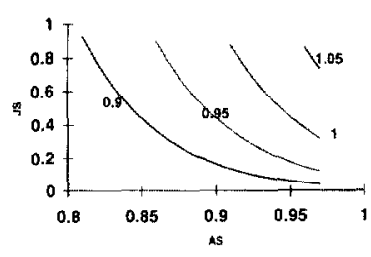

(D)

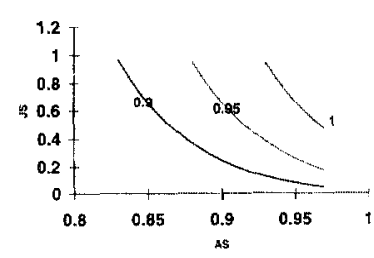

(E)
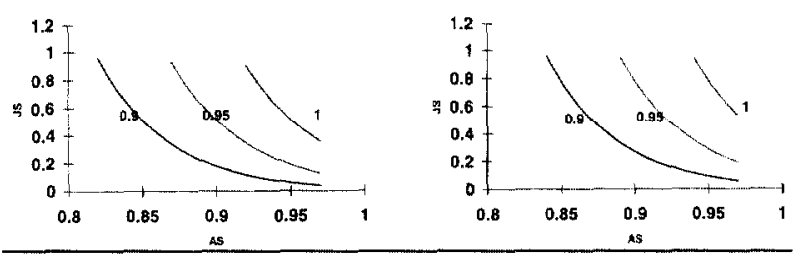

Figure 1. Asymptotic trend of the dolphin population versus adult (AS) and juvenile (IS) survival rates. The parameters AFR (age of first reproduction) and $\mathrm{IB}$ (interval between births) are expressed in years. (A): $A F R=7, I B=2 ;(B): A F R=7,1 B=3 ;(C) A F R=9, I B=2 ;(D)$ $A F R=9, I B=3 ;(E) A F R=11, I B=2 ;(F) A F R=11, I B=3$.

developped [14], this parameter varies between 2 and 3 years.

\subsubsection{Survival parameters}

- Life span $\left(t_{\max }\right)$. According to direct assessment results of cetacean populations in the Bay of Biscay, the oldest caught common dolphin was 26-year-old [14]. For simulations in this study, life span has been fixed at 30 years.

- Adult survival rate (AS). Adult phase includes all cohorts older than 2 years. It is assumed that age structure of experimental catches obtained by direct assessment corresponds to that of target population [14]. By taking into account the accidental type of catches occurring with driftnet fishery and by assuming that the natural mortality in adult life is constant, it is considered that the adult survival rate is constant. By applying the model of Siler (see [14]), the fitted adult survival rate is comprised between 0.92 and 0.97 . For calculations in this study, its value varies between 0.85 and 0.95 .

- Juvenile survival rate (JS). It is applied to juveniles of age group 1. Its value is always lower than the adult survival rate and is limited upwards by the adult survival rate squared in accordance with the hypothesis ies between 0.6 and $(0.85)^{2}, \ldots,(0.95)^{2}$. 
Table II. Sensitivities of the $\lambda$ parameter according to four parameters of the model. $\lambda=0.95 ; A S=$ adult survival rate; JS $=$ juvenile survival rate; $\mathrm{AFR}=$ age of first reproduction; $\mathrm{IB}=$ interval between births.

$-\lambda=0.95 ; \mathrm{AFR}=7$ years: $\mathrm{AS}=0.85$

variation in $\lambda$ against $\%$ variation of parameters

\begin{tabular}{|c|c|c|c|c|c|c|c|}
\hline$\triangle \mathrm{AS}(\%)$ & $\Delta \lambda$ & $\Delta \mathrm{IB}(\%)$ & $\Delta \lambda$ & $\triangle \mathrm{AFR}(\%)$ & $\Delta \lambda$ & $\Delta J S(\%)$ & $\Delta \lambda$ \\
\hline 1 & 0.016 & -50 & 0.114 & 5 & 0.000 & -10 & -0.013 \\
\hline 2 & 0.032 & -25 & 0.040 & 10 & 0.000 & -5 & -0.006 \\
\hline 3 & 0.048 & -10 & 0.013 & 20 & -0.014 & -2 & -0.002 \\
\hline 5 & 0.082 & 10 & -0.011 & 30 & -0.029 & 2 & 0.002 \\
\hline 10 & 0.173 & 25 & -0.025 & 40 & -0.029 & 5 & 0.006 \\
\hline 15 & 0.275 & 50 & -0.044 & 50 & -0.043 & 10 & 0.012 \\
\hline
\end{tabular}

$-\lambda=0.95:$ AFR $=7$ years; $\mathrm{AS}=0.95$

variation in $\lambda$ against $\%$ variation of parameters

\begin{tabular}{|c|c|c|c|c|c|c|c|}
\hline$\triangle \mathrm{AS}(\%)$ & $\Delta \lambda$ & $\Delta \mathrm{IB}(\%)$ & $\Delta \lambda$ & $\triangle \mathrm{AFR}(\%)$ & $\Delta \lambda$ & $\Delta \mathrm{JS}(\%)$ & $\Delta \lambda$ \\
\hline-20 & -0.247 & -50 & 0.062 & 5 & 0.000 & -10 & -0.008 \\
\hline-15 & -0.188 & -25 & 0.023 & 10 & 0.000 & -5 & -0.004 \\
\hline-10 & -0.128 & -10 & 0.008 & 20 & -0.003 & -2 & -0.002 \\
\hline-5 & -0.065 & 10 & -0.007 & 30 & -0.007 & 2 & 0.002 \\
\hline-2 & -0.026 & 25 & -0.016 & 40 & -0.007 & 5 & 0.004 \\
\hline-1 & -0.013 & 50 & -0.029 & 50 & -0.011 & 10 & 0.007 \\
\hline
\end{tabular}

$-\lambda=0.95 ;$ AFR $=11$ vears; $\mathrm{AS}=0.85$

variation in $\lambda$ against $\%$ variation of parameters

\begin{tabular}{|c|c|c|c|c|c|c|c|}
\hline$\triangle \mathrm{AS}(\%)$ & $\Delta \lambda$ & $\Delta \mathrm{IB}(\%)$ & $\Delta \lambda$ & $\triangle \mathrm{AFR}(\%)$ & $\Delta \lambda$ & $\Delta \mathrm{JS}(\%)$ & $\Delta \lambda$ \\
\hline 1 & 0.022 & -50 & 0.122 & -50 & 0.118 & -10 & -0.014 \\
\hline 2 & 0.045 & -25 & 0.043 & -40 & 0.094 & -5 & -0.007 \\
\hline 3 & 0.069 & -10 & 0.015 & -30 & 0.073 & -2 & -0.003 \\
\hline 5 & 0.120 & 10 & -0.012 & -20 & 0.053 & 2 & 0.003 \\
\hline 10 & 0.274 & 25 & -0.028 & -10 & 0.035 & 5 & 0.007 \\
\hline 15 & 0.481 & 50 & -0.048 & -5 & 0.017 & 10 & 0.013 \\
\hline
\end{tabular}

$-\lambda=0.95 ;$ AFR $=11$ years; $\mathrm{AS}=0.95$

variation in $\lambda$ against $\%$ variation of parameters

\begin{tabular}{|c|c|c|c|c|c|c|c|}
\hline$\triangle \mathrm{AS}(\%)$ & $\Delta \lambda$ & $\Delta \mathrm{IB}(\%)$ & $\Delta \lambda$ & $\triangle \mathrm{AFR}(\%)$ & $\Delta \lambda$ & $\triangle \mathrm{JS}(\%)$ & $\Lambda \lambda$ \\
\hline-20 & -0.300 & -50 & 0.074 & -50 & 0.019 & -10 & -0.009 \\
\hline-15 & -0.232 & -25 & 0.028 & -40 & 0.017 & 5 & -0.005 \\
\hline-10 & -0.161 & -10 & 0.010 & -30 & 0.014 & -2 & -0.002 \\
\hline-5 & -0.084 & 10 & -0.008 & -20 & 0.011 & 2 & 0.002 \\
\hline-2 & -0.035 & 25 & -0.019 & -10 & 0.008 & 5 & 0.004 \\
\hline-1 & -0.017 & 50 & -0.034 & -5 & 0.004 & 10 & 0.009 \\
\hline
\end{tabular}

Use of the terms 'juvenile survival' and 'adult survival' does not correspond rigorously to the biological reality. In fact, the adult phase equals the period beyond the first age of sexual maturity (corresponding to the minimum limit of the parameter 'age of first reproduction', AFR) while, in this study, the adult survival rate refers to age beyond 2 years. Common dolphins since the age of 2 , even if they are not yet reproductive, reach their asymptotic length and, consequently, their behavior tends to become similar to that of the adult animals [14]. For simplification, it is accepted that the survival rate tends to be stable starting from the age of 2 and, hence, will be called 'adult survival rate'.

\subsection{The final model}

By replacing fecundity of formula (4) by SR.AS/IB [25], SR by 0.5 and $t_{\max }$ by 30 years, equation (4) is modified to:

$$
\frac{\mathrm{JS}}{2 \cdot \mathrm{IB}} \cdot \sum_{i=\mathrm{AFR}}^{30} \frac{\mathrm{AS}}{\lambda^{i}}=1
$$

which is equivalent to:

$$
\frac{\mathrm{JS}}{2 \cdot \mathrm{IB}} \cdot \frac{\mathrm{AS}^{\mathrm{AFR}-1}}{\lambda^{\mathrm{AFR}}} \cdot\left[\frac{(\mathrm{AS} / \lambda)^{30-\mathrm{AFR}+1}-1}{\mathrm{AS} / \lambda-1}\right]=1
$$


Table III. Sensitivities of the $\lambda$ parameter according to four parameters of the model. $\lambda=1$; AS: adult survival rate; JS: juvenile survival rate; AFR: age of first reproduction; IB: interval between births.

$-\lambda=1 ;$ AFR $=7$ years; $\mathrm{AS}=0.85$

variation in $\lambda$ against $\%$ variation of parameters

\begin{tabular}{|c|c|c|c|c|c|c|c|}
\hline$\triangle A S(\%)$ & $\Delta \lambda$ & $\Delta \mathrm{IB}(\%)$ & $\Delta \lambda$ & $\triangle \mathrm{AFR}(\%)$ & $\Delta \lambda$ & $\Delta \mathrm{JS}(\%)$ & $\Delta \lambda$ \\
\hline 1 & 0.018 & -50 & 0.156 & 5 & 0.000 & -10 & -0.016 \\
\hline 2 & 0.037 & -25 & 0.053 & 10 & 0.000 & -5 & -0.008 \\
\hline 3 & 0.056 & -10 & 0.018 & 20 & -0.025 & -2 & -0.003 \\
\hline 5 & 0.096 & 10 & -0.015 & 30 & -0.049 & 2 & 0.003 \\
\hline 10 & 0.206 & 25 & -0.033 & 40 & -0.049 & 5 & 0.008 \\
\hline 15 & 0.331 & 50 & -0.056 & 50 & -0.070 & 10 & 0.016 \\
\hline
\end{tabular}

$-\lambda=1 ;$ AFR $=7$ years; $\mathrm{AS}=0.95$

variation in $\lambda$ against $\%$ variation of parameters

\begin{tabular}{|c|c|c|c|c|c|c|c|}
\hline$\triangle \mathrm{AS}(\%)$ & $\Delta \lambda$ & $\Delta \mathrm{IB}(\%)$ & $\Delta \lambda$ & $\triangle \mathrm{AFR}(\%)$ & $\Delta \lambda$ & $\Delta \mathrm{JS}(\%)$ & $\Delta \lambda$ \\
\hline-20 & -0.270 & -50 & 0.085 & 5 & 0.000 & -10 & -0.010 \\
\hline-15 & -0.207 & -25 & 0.031 & 10 & 0.000 & -5 & -0.005 \\
\hline-10 & -0.141 & -10 & 0.011 & 20 & -0.007 & -2 & -0.002 \\
\hline-5 & -0.073 & 10 & -0.009 & 30 & -0.015 & 2 & 0.002 \\
\hline-2 & -0.030 & 25 & -0.021 & 40 & -0.015 & 5 & 0.005 \\
\hline-1 & -0.015 & 50 & -0.036 & 50 & -0.023 & 10 & 0.010 \\
\hline
\end{tabular}

$-\lambda=1 ;$ AFR $=11$ years; $\mathrm{AS}=0.85$

variation in $\lambda$ against \% variation of parameters

\begin{tabular}{|c|c|c|c|c|c|c|c|}
\hline$\triangle \mathrm{AS}(\%)$ & $\Delta \lambda$ & $\Delta \mathrm{IB}(\%)$ & $\Delta \lambda$ & $\triangle \mathrm{AFR}(\%)$ & $\Delta \lambda$ & $\Delta \mathrm{JS}(\%)$ & $\Delta \lambda$ \\
\hline 1 & 0.026 & -50 & 0.161 & -50 & 0.264 & -10 & -0.017 \\
\hline 2 & 0.053 & -25 & 0.055 & -40 & 0.202 & -5 & -0.009 \\
\hline 3 & 0.082 & -10 & 0.019 & -30 & 0.149 & -2 & -0.003 \\
\hline 5 & 0.145 & 10 & -0.016 & -20 & 0.103 & 2 & 0.003 \\
\hline 10 & 0.339 & 25 & -0.035 & -10 & 0.064 & 5 & 0.008 \\
\hline 15 & 0.609 & 50 & -0.060 & -5 & 0.030 & 10 & 0.017 \\
\hline
\end{tabular}

$-\lambda=1 ;$ AFR $=11$ years; $\mathrm{AS}=0.95$

variation in $\lambda$ against $\%$ variation of parameters

\begin{tabular}{|c|c|c|c|c|c|c|c|}
\hline$\triangle \mathrm{AS}(\%)$ & $\Delta \lambda$ & $\triangle \mathrm{IB}(\%)$ & $\Delta \lambda$ & AAFR $(\%)$ & $\Delta \lambda$ & $\triangle \mathrm{JS}(\%)$ & $\Delta \lambda$ \\
\hline-20 & -0.327 & -50 & 0.097 & -50 & 0.048 & -10 & -0.012 \\
\hline-15 & 0.256 & 25 & 0.035 & 40 & 0.040 & -5 & -0.006 \\
\hline-10 & -0.179 & -10 & 0.012 & -30 & 0.033 & -2 & -0.002 \\
\hline-5 & -0.095 & 10 & -0.011 & -20 & 0.025 & 2 & 0.002 \\
\hline-2 & -0.039 & 25 & -0.024 & -10 & 0.017 & 5 & 0.006 \\
\hline-1 & -0.020 & 50 & -0.042 & -5 & 0.009 & 10 & 0.011 \\
\hline
\end{tabular}

\subsection{Sensitivity study}

Let $\Psi$ be a function containing the $\Theta_{1}, \Theta_{2}, \ldots, \Theta_{n}$ parameters. A response, $\mathrm{Y} \Theta$, is associated to this function: $\Psi\left\{\Theta_{1}, \Theta_{2}, \ldots, \Theta_{n}\right\}=\mathrm{Y} \Theta$. Let $\Theta_{i}$ be a parameter which is subject to a variation according to $\Delta \Theta_{i}$ and let $Y^{\prime} \Theta+\Delta \Theta$ be the new response to the $\Psi$ function.

By using a sensitivity study, it is possible to estimate the modification of the $Y \Theta$ response into $Y^{\prime} \Theta+\Delta \Theta$ against the variation in $\Theta_{i}$ parameter, according to $\Delta \Theta_{i}$. Absolute or relative sensitivities exist; in the latter case, the modification of the $Y \Theta$ response into $Y^{\prime} \Theta+$ $\Delta \Theta$ is expressed in percentage with respect to the variation of $\Theta_{i}$ into $\Theta_{i}+\Delta \Theta_{i}$, which is equally expressed in percentage $\left(100 \cdot \Delta \Theta_{i} / \Theta_{i}\right)$.
A sensitivity study is carried out in two different ways depending on whether the models are linear or non-linear.

In the case of linear models, it is possible to obtain an exact analytical solution of the $\mathrm{Y} \Theta$ response in terms of modification into $Y^{\prime} \Theta+\Delta \Theta$ against the variation in the $\Theta_{i}$ parameter, according to $\Delta \Theta_{i}$; the increment $\Delta \Theta_{i}$ is not necessarily infinitely small. In the case of non-linear models, analytical investigation of errors is impossible and approximative methods must be used, e.g. delta methods based on the approximate nature of a function in an infinite Taylor series $[5,6,9$, $10,11,18,19]$; those approximations are valid only if the variation increment is too small comparatively to 
Table IV. Sensitivities of the $\lambda$ parameter according to four parameters of the model. $\lambda=1.05$; AS: adult survival rate; JS: juvenile survival rate; AFR: age of first reproduction; IB: interval between births.

$-\lambda=1.05 ;$ AFR $=7$ years: $\mathrm{AS}=0.85$

variation in $\lambda$ against $\%$ variation of parameters

\begin{tabular}{|c|c|c|c|c|c|c|c|}
\hline$\Delta \wedge S(\%)$ & $\Delta \lambda$ & $\triangle \mathrm{IB}(\%)$ & $\Delta \lambda$ & $\triangle \mathrm{AFR}(\%)$ & $\Delta \lambda$ & $\Delta \mathrm{JS}(\%)$ & $\Delta \lambda$ \\
\hline 1 & 0.021 & -50 & 0.202 & 5 & 0.000 & -10 & -0.021 \\
\hline 2 & 0.043 & -25 & 0.068 & 10 & 0.000 & -5 & -0.010 \\
\hline 3 & 0.065 & -10 & 0.023 & 20 & -0.040 & -2 & -0.004 \\
\hline 5 & 0.112 & 10 & -0.019 & 30 & -0.074 & 2 & 0.004 \\
\hline 10 & 0.241 & 25 & -0.042 & 40 & -0.074 & 5 & 0.010 \\
\hline 15 & 0.393 & 50 & -0.070 & 50 & -0.105 & 10 & 0.021 \\
\hline
\end{tabular}

$-\lambda=1.05 ; \mathrm{AFR}=7$ years: $\mathrm{AS}=0.95$

variation in $\lambda$ against $\%$ variation of parameters

\begin{tabular}{|c|c|c|c|c|c|c|c|}
\hline$\triangle \mathrm{AS}(\%)$ & $\Delta \lambda$ & $\Delta \mathrm{IB}(\%)$ & $\Delta \lambda$ & $\triangle \mathrm{AFR}(\%)$ & $\Delta \lambda$ & $\triangle \mathrm{JS}(\%)$ & $\Delta \lambda$ \\
\hline 20 & 0.296 & 50 & 0.118 & 5 & 0.000 & 10 & 0.013 \\
\hline-15 & -0.228 & -25 & 0.041 & 10 & 0.000 & -5 & -0.007 \\
\hline-10 & -0.157 & -10 & 0.014 & 20 & -0.014 & -2 & -0.003 \\
\hline-5 & -0.082 & 10 & -0.012 & 30 & -0.028 & 2 & 0.003 \\
\hline-2 & -0.033 & 25 & -0.027 & 40 & -0.028 & 5 & 0.006 \\
\hline-1 & -0.017 & 50 & -0.046 & 50 & -0.042 & 10 & 0.013 \\
\hline
\end{tabular}

$-\lambda=1.05 ; \mathrm{AFR}=11$ years; $\mathrm{AS}=0.85$

variation in $\lambda$ against $\%$ variation of parameters

\begin{tabular}{|c|c|c|c|c|c|c|c|}
\hline$\Delta \mathrm{AS}(\%)$ & $\Delta \lambda$ & $\triangle \mathrm{IB}(\%)$ & $\Delta \lambda$ & $\triangle \mathrm{AFR}(\%)$ & $\Delta \lambda$ & $\triangle \mathrm{JS}(\%)$ & $\Delta \lambda$ \\
\hline 1 & 0.030 & -50 & 0.206 & -50 & 0.521 & -10 & -0.021 \\
\hline 2 & 0.063 & -25 & 0.138 & -40 & 0.384 & -5 & -0.011 \\
\hline 3 & 0.097 & -10 & 0.023 & -30 & 0.273 & -2 & -0.004 \\
\hline 5 & 0.172 & 10 & -0.019 & -20 & 0.183 & 2 & 0.004 \\
\hline 10 & 0.411 & 25 & -0.043 & -10 & 0.109 & 5 & 0.011 \\
\hline 15 & 0.749 & 50 & -0.073 & -5 & 0.050 & 10 & 0.021 \\
\hline
\end{tabular}

$-\lambda=1.05 ; \mathrm{AFR}=11$ years; $\mathrm{AS}=0.95$

variation in $\lambda$ against $\%$ variation of parameters

\begin{tabular}{|c|c|c|c|c|c|c|c|}
\hline$\Delta \mathrm{AS}(\%)$ & $\Delta \lambda$ & $\triangle \mathrm{IB}(\%)$ & $\Delta \lambda$ & $\triangle \mathrm{AFR}(\%)$ & $\Delta \lambda$ & $\Delta \mathrm{JS}(\%)$ & $\Delta \lambda$ \\
\hline-20 & -0.358 & -50 & 0.128 & -50 & 0.110 & -10 & -0.015 \\
\hline-15 & -0.282 & -25 & 0.045 & -40 & 0.089 & 5 & 0.007 \\
\hline-10 & -0.200 & -10 & 0.016 & -30 & 0.069 & -2 & -0.003 \\
\hline-5 & -0.107 & 10 & -0.013 & -20 & 0.051 & 2 & 0.003 \\
\hline-2 & -0.045 & 25 & -0.030 & -10 & 0.033 & 5 & 0.007 \\
\hline-1 & -0.023 & 50 & -0.051 & -5 & 0.017 & 10 & 0.014 \\
\hline
\end{tabular}

the value of the parameter $\Theta_{i}$. In the present study, only the first case has been used.

\subsection{The dolphin model and the sensitivity study}

The linear model used for the dolphin does not require any partial derivatives. The calculations are general and are not specific to just one particular point. The variation increment of a parameter is not always very small.

It is a question of calculating the effect on the increase rate of the population, or the effect on the first eigen value $(\lambda)$, of a change in each of the four model parameters (AFR, IB, AS, JS), while the other model parameters (SR, $t_{\text {max }}$ ) are constant. At first, the correlations between these parameters are not taken into account. Thus, crossed sensitivities (or co-sensitivities) are not analyzed.

Let $\Theta_{i}$ be one of the parameters of the model and $\Psi$ the function described by the Lotka equations (3) to (5). If the variation increment of this $\Delta \Theta_{i}$ parameter is used as input, then the modification in the response of the first eigen value, $\lambda$, expressed by $\Delta \lambda$, can be calculated:

$$
\Psi\left\{\Theta_{i}+\Delta \Theta_{i} ; \lambda+\Delta \lambda\right\}=\Psi\left\{\Theta_{i} ; \lambda\right\}
$$


Figure 2. Sensitivities of $\lambda$ against four parameters of the model. $\lambda=1$; AFR $=7$ years. Initial values of $\mathrm{JS}$ and $\mathrm{IB}$ : (i) for $\mathrm{AS}=0.85$, $\mathrm{JS}=0.723, \quad \mathrm{IB}=0.890$; (ii) for $\mathrm{AS}=0.90$, JS $=0.810, \quad \mathrm{IB}=1.981 ;$ (iii) for $\mathrm{AS}=0.95$, $\mathrm{JS}=0.903, \mathrm{IB}=4.697$.

(A)

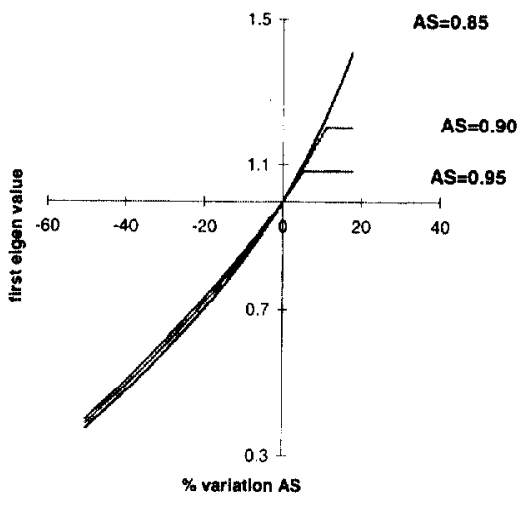

(C)

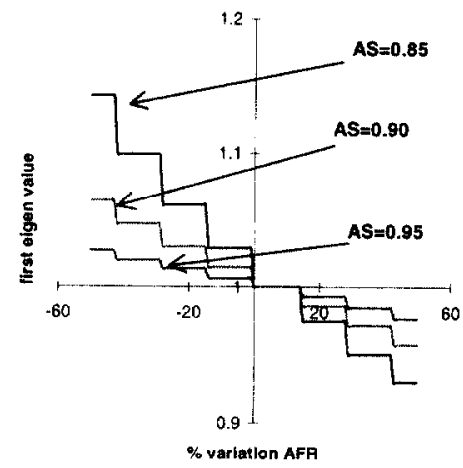

(日)

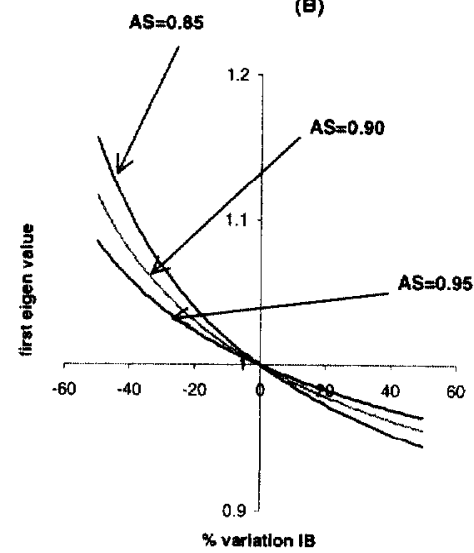

(D)

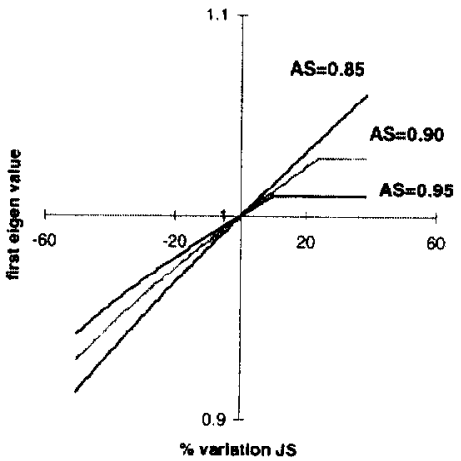

\subsubsection{Age of first reproduction sensitivity}

If we inpul a variation in this parameter according to $\triangle A F R$, we find $\Delta \lambda$ in the following way:

$$
\begin{aligned}
& \frac{\mathrm{JS}}{2 \cdot \mathrm{IB}} \cdot \sum_{i=\mathrm{AFR}}^{30} \frac{\mathrm{AS}^{i-1}}{\lambda^{i}}= \\
& \frac{\mathrm{JS}}{2 \cdot \mathrm{IB}} \cdot \sum_{i=\mathrm{AFR}+\Delta \mathrm{AFR}} \frac{\mathrm{AS}^{i-1}}{(\lambda+\Delta \lambda)^{i}}
\end{aligned}
$$

After simplification, by expressing $\triangle \mathrm{AFR} / \mathrm{AFR}$ as $\alpha$, we obtain:

$$
\sum_{i=\mathrm{AFR}}^{30} \frac{\mathrm{AS}^{i-1}}{\lambda^{i}}=\sum_{i=\mathrm{AFR} \cdot(1+\alpha)}^{30} \frac{\mathrm{AS}^{i-1}}{(\lambda+\Delta \lambda)^{i}}
$$

$\mathrm{NB}: \mathrm{AFR} \cdot(1+\alpha)$ is rounded off.

This equation shows that the sensitivities are dependent solely on combinations of the initial values of the AS and AFR parameters; initial values of the IB and JS parameters have no influence on the results.

Aquat. Living Resour. 11 (6) (1998)

\subsubsection{Interval between birth sensitivity}

If we proceed as previously by expressing $\triangle I B / I B$ as $\alpha$, we obtain:

$$
\sum_{i=\mathrm{AFR}}^{30} \frac{\mathrm{AS}^{i-1}}{(\lambda+\Delta \lambda)^{i}}=(1+\alpha) \cdot \sum_{i=\mathrm{AFR}}^{30} \frac{\mathrm{AS}^{i-1}}{\lambda^{i}}
$$

\subsubsection{Adult survival rate sensitivity}

Expressing $\triangle \mathrm{AS} / \mathrm{AS}$ as $\alpha$, we obtain:

$$
\sum_{i=\mathrm{AFR}}^{30} \frac{\mathrm{AS}^{i-1}}{\lambda^{i}}=\sum_{i=\mathrm{AFR}}^{30} \frac{\mathrm{AS}^{i-1} \cdot(1+\alpha)^{i-1}}{(\lambda+\Delta \lambda)^{i}}
$$

\subsubsection{Juvenile survival rate sensitivity}

If $\Delta \mathrm{JS} / \mathrm{JS}=\alpha$, we write:

$$
\sum_{i=\mathrm{AFR}}^{30} \frac{\mathrm{AS}^{i-1}}{\lambda^{i}}=(1+\alpha) \cdot \sum_{i=\mathrm{AFR}}^{30} \frac{\mathrm{AS}^{i-1}}{(\lambda+\Delta \lambda)^{i}}
$$


(A)

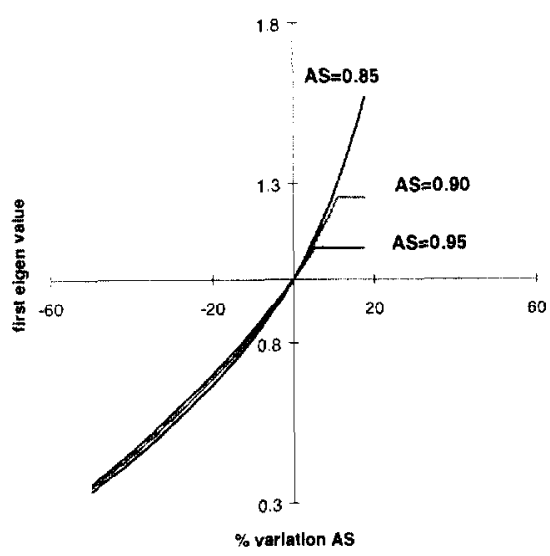

(C)

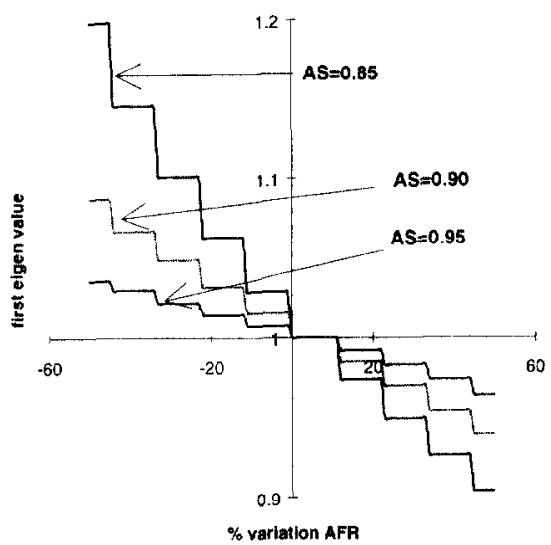

(B)

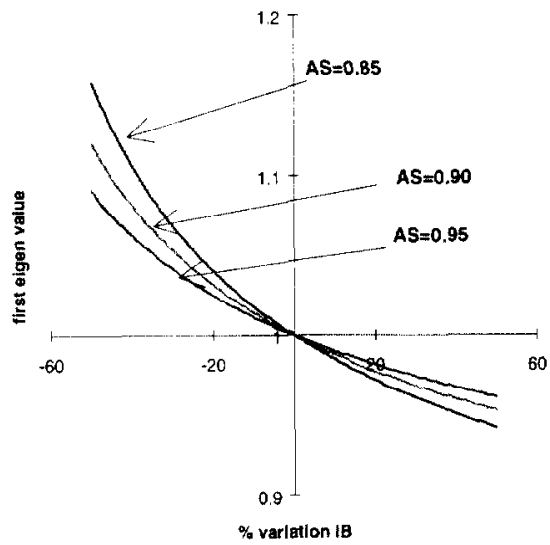

(D)

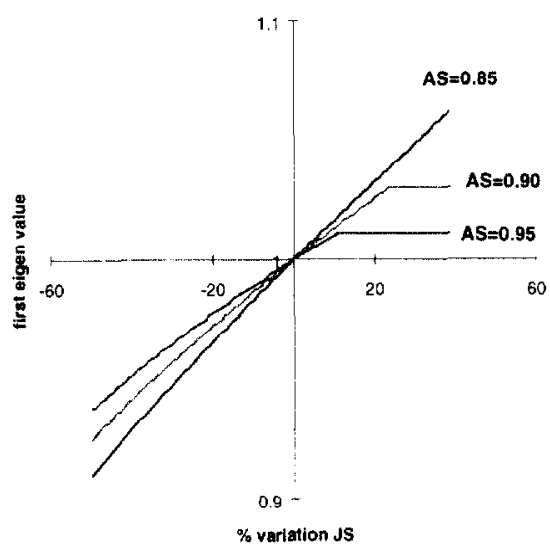

Figure 3. Sensitivities of $\lambda$ against four parameters of the model. $\lambda=1$; $A F R=9$ years. Initial values of $J S$ and IB: (i) for $\mathrm{AS}=0.85, \mathrm{JS}=0.723$, $\mathrm{IB}=0.638$; (ii) for $\mathrm{AS}=0.90$, $\mathrm{JS}=0.810, \quad \mathrm{IB}=1.572 ; \quad$ (iii) for $\mathrm{AS}=0.95, \mathrm{JS}=0.903, \mathrm{IB}=4.050$

\section{RESULTS}

The dolphin population of the Bay of Biscay presents an asymptotic trend close to stability $(\lambda=1)$. However, in many cases of our simulations (26 of 36 combinations of values of the four parameters of the model; table I), the population is characterized by a weakly decreasing trend, mainly when the AFR (age of first reproduction) and IB (interval between births) parameters increase and the AS (adult survival rate) and JS (juvenile survival rate) parameters decrease (figure 1).

As mentioned above, AFR and AS are the only parameters with initial values that can influence the increase in population rate $(\lambda)$ in terms of sensitivities. Thus, the results are presented according to AS and AFR combinations (tables II-IV, figures 2-4). The sensitivities are estimated from variations in the parameters (expressed in percentage).

The results show that, in terms of sensitivities, it is the adult survival parameter (AS) which exerts the greatest effect on the increase in population rate expressed by the parameter $\lambda$. Next is the time-interval between births (IB) which defines the multiplying elements of fecundity between AFR and the animal's life span (fixed here at 30 years).

However, the AFR and especially the JS parameters have only a slight effect. In fact, the former defines the number of non-zero elements in the Lotka equation. As the animal's life span is high, there are few modifications in the number of polynomials as regards eigen values if the AFR increases by a few years. The JS parameter is only involved as a multiplying element; its influence is limited to the number of survivors which move up to age group 2 .

In summary, the order of the parameter sensitivities was: $\mathrm{AS}>\mathrm{IB}>\mathrm{AFR}>\mathrm{JS}$.

\subsection{Adult survival rate (AS)}

We found that the higher the AFR, the greater the effect on $\lambda$. If the AFR is hypothesized as being 7 years, an increase of $10 \%$ in the survival rate initially fixed at 0.85 triggers an increase of $18 \%$ of the population for $\lambda=0.95(\Delta \lambda=0.173), 21 \%$ for $\lambda=1$ $(\Delta \lambda=0.206)$ or $23 \%$ for $\lambda=1.05(\Delta \lambda=0.241)$. When 
(A)

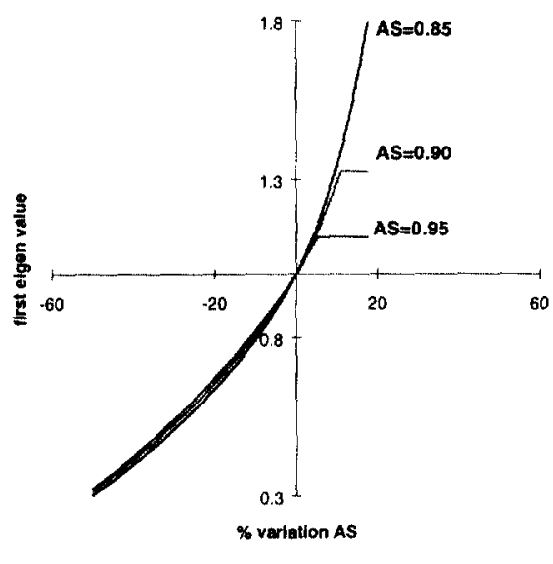

(C)

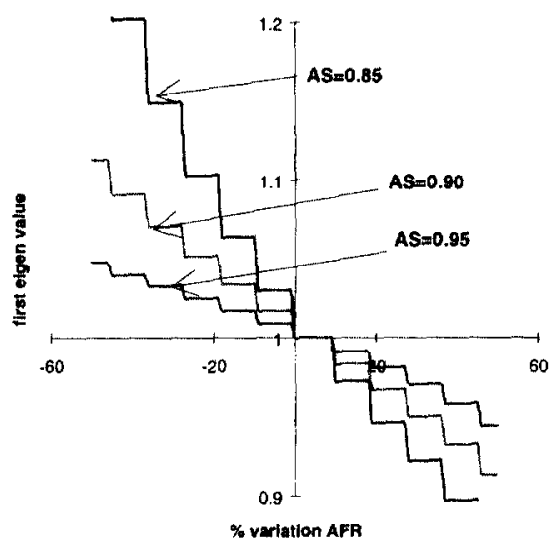

(B)

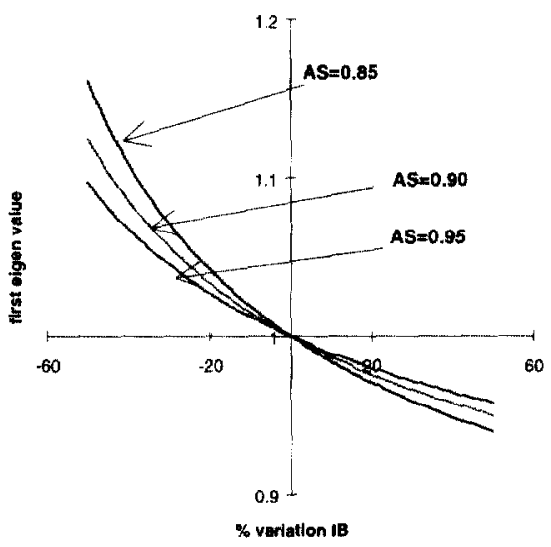

(D)

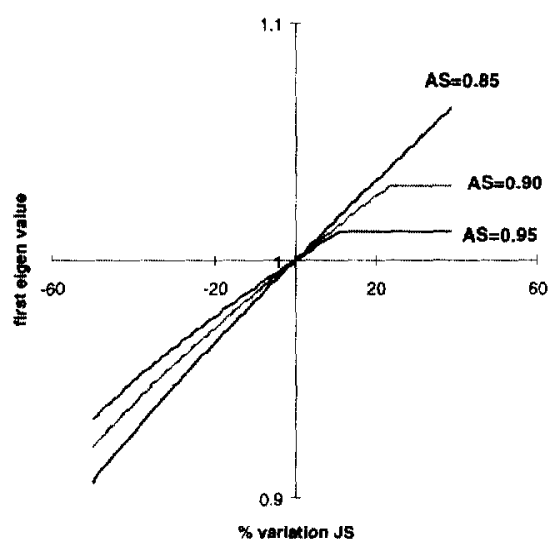

the AFR is set at 11 years and there is an increase of $10 \%$ in AS (initially equal to 0.85 ), the population grows by $29 \%(\lambda=0.95), 34 \%(\lambda=1)$ or $39 \%$ $(\lambda=1.05)$.

\subsection{Interval between births (IB)}

It was found that the lower the AS, the greater the effect of a modification of the IB parameter on $\lambda$. However, the effect of this parameter on $\lambda$ is hardly dependent on AFR. An increase from 2 to 3 years in IB induces a fall in $\lambda$ equal to $4.6 \%$ for $\lambda=0.95$ $(\Delta \lambda=-0.044), 5.6 \%$ for $\lambda=1(\Delta \lambda=-0.056)$ or $6.7 \%$ for $\lambda=1.05(\Delta \lambda=-0.070)$ for two of the AFR and AS parameters, namely 7 years and 0.85 , respectivcly. If AS is $0.95, \lambda$ decreases by $3.1 \%$ (for $\lambda=0.95$ ), $3.6 \%$ (for $\lambda=1$ ) or $4.4 \%$ (for $\lambda=1.05$ ) when IB increases from 2 to 3 years. We note that a decrease in IB has a greater effect on $\lambda$ than that produced by a symmetrical increase.

\subsection{Age of first reproduction (AFR)}

We found that the higher the AS level, the lesser the effect produced by a modification in the AFR. If AS is 0.85 , an increase of $20 \%$ in AFR initially fixed to 7 years triggers a decrease of $1.5 \%$ in $\lambda$ for $\lambda=0.95$ $(\Delta \lambda=-0.014), 2.5 \%$ for $\lambda=1(\Delta \lambda=-0.025)$ or $3.8 \%$ for $\lambda=1.05(\Delta \lambda=-0.040)$. At 0.95 , the same scenario leads to a decrease of $0.3,0.7$ or $1.3 \%$, respectively. Conversely, a AFR fall from $20 \%$ for an initial value of 11 years produces a $\lambda$ increase of $5.6 \%$ (for $\lambda=0.95$ ), $10.3 \%$ (for $\lambda=1$ ) or $17.4 \%$ (for $\lambda=1.05$ ) when AS is equal to 0.85 and $1.2 \%$ (for $\lambda=0.95$ ), $2.5 \%$ (for $\lambda=1$ ) or $4.9 \%$ (for $\lambda=1.05$ ) when AS is fixed at 0.95 . Unlike the IB parameter, no significant dissymmetrical trends were shown in the AFR sensitivity study.

\subsection{Juvenile survival (JS)}

When the adult survival rate (AS) increases, the effect of JS on $\lambda$ diminishes. Modifications in JS levels induce only slight variations in $\lambda$ (about \pm 1 to $\pm 2 \%$ ). 


\section{DISCUSSION}

\subsection{Study context and model simplifications}

The parameter values do not correspond exactly to a biological reality. Taking into account the constant values, notably in the case of expected fecundity (including the interval between births, IB) and the adult survival rate (AS), it represents the most simplified example. Expected fecundity reaches a maximum value at age 13-17 years and decreases beyond this age [14]. The survival rate is stabilized starting with age group 2 at a ceiling of 0.95 and decreases gradually beyond 25 years of age.

\subsection{Constancy of parameters and compensatory process}

Compensatory processes, a partial compensation of the diminution of the spawning biomass via recruitment rate, increase when the spawning biomass decreases [4]. On the other hand, in the case of several stocks, an abundance rarefaction can induce the inverse phenomenon: diminution of the spawning biomass leads to a diminution in the recruitment rate according to a depensatory process [12]. In the case of the discrete model applied to the common dolphin, this kind of process has been neglected. It has been assumed that the fecundity rate included in the transition matrix and depending on two parameters (age of first reproduction, AFR, and interval between births, IB) is not affected by a modification of the survival rate. Liermann and Hilborn [21] analyzed depensation and hypercompensation processes in four taxonomic groups and deduced that the most likely values fell close to or within the range of no depensation. Myers et al. [23] have studied the self-regulation mechanisms of many marine populations and they have concluded that there exists very few cases characterized by a depensatory phenomenon. Furthermore, even in these rare cases, it is not obvious that observed trends correspond to real cases of acceleration of stock decline because of interannual resource variability induced by the chaotic relationship between stock and recruitment.
Rare cases of stock collapses have been observed in marine life history.

The developed mode of marine mammal reproduction encourages the consideration that the most probable regulations would be compensatory in nature. According to this assumption, the discrete model of this study, without taking into account the correlations between survival and fecundity parameters, overestimates the effects induced by a reduction in the survival rate on the increase in the dolphin population rate. However, the very broad distribution of several marine populations like marine mammals does not allow for the consideration that hypercompensation is more probable than depensation [21].

\section{CONCLUSION}

Studies conducted on the common dolphin population of the Bay of Biscay have estimated that the additional mortality induced by drifnet fishery is equal to $0.8 \%$ per year [14]. The same author calculates thc total mortality rate by using the Siler model: its value is comprised between 3 and $8 \%$ per year. By maintaining driftnet fishing effort at the level of recent years, the component due to fishing mortality is less than that associated to natural causes. Consequently, risk for the common dolphin population is not significantly likely. Nevertheless, the sensitivity analyses of the linear model have shown the dominance of parameters linked to survival rather than fecundity in terms of effects on increase in the population rate. Despite the simplifications done in this study relating to the constancy of survival parameters all along an animal's life and to the absence of correlations between survival and fecundity parameters, the main conclusion would be that driftnet fishing effort developed since the latter half of the 1980s was sustainable for the common dolphin population. However, many combinations of input parameters of the model give a weakly decreasing trend in dolphin populations and, it is not possible to consider that marine mammals are characterized by compensatory or depensatory phenomena which can or not improve a population status.

\section{REFERENCES}

[1] Antoine L., Des dauphins, des thons et des pêcheurs; le filet maillant dérivant en Atlantique Nord, Equinoxe 33 (1990) 11-14.

[2] Antoine L., Danel P., Captures comparées de deux types de filets dérivants en 1991: premiers résultats, Rec. Doc. Sci. ICCAT 39 (1992) 241-246.

[3] Barlow J., Boveng P., Modelling age-specific mortality for marine mammal populations, Mar. Mammal Sci. 7 (1991) 50-65.

[4] Beverton R.J.H., Holt S.J., On the dynamics of exploited fish populations, UK Min. Agric. Fish Food Fish. Invest. (Ser. 2) 19 (1957) 533 p.

[5] Chevaillier P., Méthodes d'étude de la dynamique des espèces récifales exploitées par une pêcherie artisanale tropicale: le cas de la Martinique, thèse dr-Ing., ENSA Rennes, 1990, 367 p.

[6] Chevaillier P., Laurec A., Logiciels pour l'évaluation des stocks de poisson. ANALEN: Logiciel d'analyse des données de capture par classe de taille et de simulation des pêcheries multi-engins avec analyse de sensi- 
bilité, FAO, Doc. Tech. Pêches n ${ }^{\circ} 101$, suppl. 4, 1990, $124 \mathrm{p}$.

[7] Eberhardt L.L., Population dynamics of the Pribilof fur seals, in: Fowler Ch.W., Snith T.D. (Eds.), Dynamics of Large Mammal Populations, Wiley J., 1981, pp. 197220.

[8] Eberhardt L.L., Assessing the dynamics of wild populations, J. Wildl. Manag. 49 (1985) 997-1012.

[9] Fifas S., Analyse et modélisation des paramètres d'exploitation du stock de coquilles Saint-Jacques (Pecten maximus L.) en baie de Saint-Brieuc (Manche Ouest, France), thèse, université de Brest, 1991, 422 p.

[10] Fifas S., Berthou P., Un modèle d'efficacité d'une drague expérimentale à coquilles Saint-Jacques (Pecten maximus L.). Exemple de la pêcherie de la baie de Saint-Brieuc (Manche, France). Étude des sensibilités, CIEM, Stat. Comm., C.M. 1992/D:27, 1992, 20 p.

[11] Fifas S., Jézéquel M., La structure démographique des captures de la coquille Saint-Jacques (Pecten maximus L.) en baie de Saint-Brieuc (Manche, France). Estimation des variances et des biais. Approche stochastique de l'analyse des cohortes, CIEM, Stat. Comm., C.M. 1991/D:28, 1991, 21 p.

[12] Fox Jr W.W., A general life history exploited population simulator with pandalid shrimp as an example, Fish. Bull. US 71 (1973) 1019-1028.

[13] Getz W.M., Haight R.G., Population harvesting. Demographic models of fish, forest and animal resources, Princeton Univ. Press, New Jersey, 1989, 392 p.

[14] Goujon M., Captures accidentelles du filet maillant dérivant et dynamique des populations de dauphins au large du golfe de Gascogne, thèse dr., ENSA Rennes, $\mathrm{n}^{\circ} 96-9,1996,239 \mathrm{p}$.

[15] Goujon M., Antoine L., Collet A., Incidental catches of cetaceans by the French albacore tuna driftnet fishery: preliminary results, ICES Statutory meeting 13, 1993, $17 \mathrm{p}$.

[16] Goujon M., Antoine L., Collet A., Fifas S., Approche de l'impact écologique de la pêcherie thonière au filet maillant dérivant en Atlantique nord-est, Rapp. Ifremer, 1993, $47 \mathrm{p}$.

[17] Harwood J., Managing grey seal populations for optimum stability, in: Fowler Ch.W., Smith T.D. (Eds.), Dynamics of Large Mammal Populations, Wiley J., $1981,477 \mathrm{p}$.

[18] Laurec A., Les méthodes delta en halieutique. Evaluation des sensibilités, approximation des biais et variances à l'aide des développements limités, Rapp. Ifremer, 1986, $64 \mathrm{p}$.

[19] Laurec A., Mesnil B., Analytical investigations of errors in mortality rates estimated from length distribution of catches, in: Pauly D., Morgan G.R. (Eds.), Length Based Methods in Fisheries Research ICLARM Conf. Proc. 13, Manila, Philippines and Kuwait Inst. Sci. Res., 1987, pp. 239-282.

[20] Leslie P.H., On the use of matrices in certain population mathematics, Biometrika 33 (1945) 183-212.

[21] Liermann M., Hilborn R., Depensation on fish stocks: A hierarchic Bayesian meta-analysis, Can. J. Fish. Aquat. Sci. 54 (1997) 1976-1984.

[22] Lotka A.J., A contribution to the theory of self-renewing aggregates, with special inference to industrial replacement, Ann. Math. Stat. 10 (1939) 1-25.

[23] Myers R.A., Barrowman N.J., Hutchings J.A., Rosenberg A.A., Population dynamics of exploited fish stocks at low population levels, Science 269 (1995) 11061109.

[24] Perrin W.F., Reilly S.B., Reproductive parameters of dolphins and small whales of the family Delphinidae, in: Perrin W.F., Brownell Jr R.L., DeMaster D.P. (Eds.), Reproduction of Whales, Dolphins and Porpoises, Rep. Int. Whaling Comm. 6, 1984, pp. 97-133.

[25] Reilly S.B., Barlow J., Rates of increase in dolphin population size, Fish. Bull. 84 (1986) 527-533.

[26] Woodley T.H., Read A.J., Potential rates of increase of a harbour porpoise (Phocoena phocoena) population subjected to incidental mortality in commercial fisheries, Can. J. Fish. Aquat. Sci. 48 (1991) 2429-2435. 